\title{
Técnica de Tinta China en células adherentes en cultivo
}

\author{
China ink in adherents ceil in culture
}

Adriana Ordóñez Vásquez ${ }^{1}$, Lorenza Jaramillo Gómez ${ }^{2}$, Margie Ibata ${ }^{3}$, Fernando Suárez-Obando

\section{Resumen}

Objetivo. Implementar la utilización de Tinta China como alternativa para visualizar, cambios a nivel de matriz y pared celular, en células vivas adheridas en cultivo, antes y después de la exposición a una sustancia toxica. Métodos. Se implementó la Tinta China, como técnica de contraste en microscopia óptica, comparando la nitidez observada (adecuada apreciación del borde de las estructuras) entre frascos de cultivo de células troncales de médula ósea de rata (CTMO) expuestos al glicoalcaloide tóxico $\alpha$-solanina. Las diferencias de nitidez se compararon entre los diversos tratamientos, con test exacto de Fisher. Resultados. La tinción con Tinta China permitió identificar con nitidez los cambios fenotípicos celulares anormales, secundarios a la exposición del citotóxico en células adherentes en cultivo ( $p$ $<0.0001)$. Conclusiones. La Tinta China es útil en la visualización nítida de las células CTMO y de los efectos producidos por el glicoalcaloide $\alpha$-solanina en células adheridas en cultivo. Es un método sencillo que aporta al entendimiento del efecto que diversas sustancias producen en las CTMO en cultivo.

\section{Palabras clave}

Tinta China, solanina, células madre, In Vitro Imagen Óptica

\section{Abstract}

Objective. To implement the use of China ink, as an alternative technique, to display morphological changes in cellular wall and cellular matrix in adherent living cells in culture flask, before and after exposure to a toxic substance. Methods. China Ink was implemented as a contrast technique in optical microscopy, by comparing observed sharpness (proper appreciation of edge structures) from cultures of bone marrow stem cells (CTMO) exposed to the toxic glycoalkaloid $\alpha$-solanine. The sharpness differences were compared among the diverse treatments with Fisher's exact test. Results. China Ink staining clearly helps to identify abnormal phenotypic changes, secondary to cytotoxic exposure in adherent cells in culture ( $\mathrm{p}$ <0.0001). Conclusions. China Ink is useful in clearly displaying the CTMO cells and the effects of the $\alpha$-solanine glycoalkaloid in adherent cells in culture. It is a simple method that contributes to the understanding of the effect of various substances on CTMO in culture.

\section{Keywords}

China Ink, Solanine, Stem Cells, In Vitro, Optical Imaging

1 Instituto de Genética Humana, Facultad de Medicina, Pontificia Universidad Javeriana.

${ }^{2}$ Centro de Investigaciones Odontológicas, Facultad de Odontología, Pontificia Universidad Javeriana.

${ }^{3}$ Departamento de Farmacia, Grupo de Farmacogenética del Cáncer. Universidad Nacional de Colombia.

Institución donde se realizó el estudio: Pontificia Universidad Javeriana.

Correspondencia: fernando.suarez@javeriana.edu.co

Recibido: 02-02-2016 Aceptado: 01-04-2016 


\section{Introducción}

La citotoxicidad es un parámetro biológico que se define como una alteración de las funciones celulares básicas que conlleva a un daño fenotípico. El análisis de citotoxicidad es de uso corriente en el laboratorio, debido a la facilidad de su medición y por el empleo de parámetros de clasificación de uso común, como la relación dosis dependiente de Paracelso, que permiten diferenciar si el compuesto químico al que se exponen las células, se puede catalogar como tóxico o como medicamento. Lo cual, casi siempre depende de si la sustancia a concentraciones bajas, modula acciones fisiológicas, mientras que, a concentraciones más altas, genera efectos tóxicos, incluyendo apoptosis y dańos en la membrana (1).

Las células de mamífero en cultivo, después de interactuar con una toxina y de manera independiente del mecanismo de reacción a la noxa, sufren una serie de cambios estructurales y morfológicos drásticos, que conducen entre otros, a la pérdida de integridad de la membrana (2). Estos cambios, así como la viabilidad celular, pueden ser evaluados mediante ensayos de absorción de colorantes, tales como el azul de tripán, que traspasa las membranas alteradas y tiñe solamente las células muertas (3) y otros, como el rojo neutro, que se acumula en los lisosomas de las células vivas (4). Sin embargo, al igual que los ensayos fluorescentes, estos métodos al ser invasivos, siempre afectan la viabilidad celular.

La integridad de la membrana, luego de la exposición tóxica, también se puede evaluar mediante ensayos de liberación de enzimas, como por ejemplo la medición de LDH (lactato deshidrogenasa), la medición de adenilato quinasa (5) o la cuantificación de GAPDH (deshidrogenasa gliceraldehído-3-fosfato deshidrogenasa) (6). Sin embargo, estos ensayos tienen limitaciones, que incluyen, además del alto costo, la adición múltiple y repetitiva de reactivos, baja sensibilidad, bajo rendimiento, mala linealidad y la necesidad de lavados e intercambios de medio de cultivo (7).

De otra parte, las técnicas antes mencionadas, hacen referencia a tinción de células en suspensión, las cuales se pueden complementar con métodos simples para mejorar la nitidez de la observación, tales como la adaptación de microscopia de contraste de fase, así como la coloración directa de las preparaciones $(8,9)$. Sin embargo, no se evidencia en la literatura referencias a la aplicación directa de colorantes (tinciones no invasivas), en células adherentes en cultivo, con el objetivo de determinar los cambios morfológicos posteriores a la exposición de alguna sustancia en particular.

Teniendo en cuenta la necesidad de incluir estudios de citotoxicidad en cultivos, para el desarrollo de diversos análisis, tales como los efectos celulares de nuevos fármacos o el estudio de sustancias con potencial citotóxico (10), es preciso implementar nuevas técnicas asequibles o incluso modificaciones de métodos comunes, con el objetivo de lograr una cualificación y cuantificación nítida y sencilla de los cambios celulares posteriores a la exposición a diversas sustancias. En el presente artículo se propone validar a la tinción con tinta China, como un modelo de técnica asequible y rápida que permite observar de manera nítida características celulares iniciales y cambios posteriores de estas, logrando mejor desempeño que la observación directa de células adheridas con microscopia invertida. La tinta China, es la base de la tinción negativa en microscopía óptica y permite contrastar las muestras mediante una sustancia opaca a los fotones, que aumenta el contraste con el medio externo, es decir, que tińe el fondo y resalta las células que quedan sin color, de tal modo que es una tinción no invasiva; es un método rápido y económico que no requiere una etapa de hidrólisis en la preparación y que además, muestra una buena correlación con técnicas costosas que consumen más tiempo (11). 


\section{Materiales y Métodos}

Con el objetivo de describir el procedimiento para implementar la Tinta China como método directo de visualización de los cambios morfológicos de células adherentes en cultivo, luego de la exposición a una sustancia citotóxica, se describe el modelo experimental empleado in vitro para valorar la toxicidad del compuesto químico.

\section{Cultivo celular}

El cultivo celular del modelo se realizó con CTMO (Células troncales de medula ósea de ratas Lewis), células indiferenciadas, adherentes, que crecen en una monacapa característica. Las células fueron extraídas, cultivadas y fenotipificadas con citometría de flujo como CD45- CD45+, CD29+, CD90+, CD71+ y CD106+, de acuerdo a los protocolos estandarizados del CIO (Centro de Investigaciones Odontológicas) de la Pontificia Universidad Javeriana (12).

Las CTMO provenientes de cultivos primarios, fueron distribuidas en 4 frascos de cultivo celular de $25 \mathrm{~cm}^{3}$ de cuello inclinado. Cuando cubrieron el 90\% de la superficie de crecimiento (confluencia) $\mathrm{y}$ antes de que su multiplicación fuera inhibida al hacer contacto entre sí (quiescencia), se procedió a cuantificar las células, por conteo directo en cámara de Newbawer, estableciendo un conteo de 2.000.000 células / frasco.

\section{Agente citotóxico}

Como agente citotóxico se utilizó la $\alpha$-solanina (Solatunin; $\alpha$-Solanine), (C45H73NO15). Glicoalcaloide trisacárido constituido por glucosa, galactosa, ramnosa, y un anillo de solanidina, adquirido comercialmente con una pureza $>95 \%$, según (Referencia sc-252340 Santa Cruz Biotecnology). La $\alpha$-solanina es insoluble en agua, cloroformo y éter, por lo que fue solubilizada utilizando $\mathrm{NaCl}$ al $0.45 \%, \mathrm{CH} 3 \mathrm{COOH}$ al $0.25 \%$, y DMSO (Dimetilsulfoxido) al 0.2\% según protocolo reportado por Ming-Kun (13).

Cada uno de los frascos de cultivo fue marcado según el tratamiento, así: frasco $1 /$ ensayo $\mathrm{A}$ (sin solanina - sin tinta China), Frasco 2 / ensayo B (sin solanina - con tinta China), Frasco 3 / ensayo C (con solanina - sin tinta China) y Frasco $4 /$ ensayo D (con solanina-con tinta China).

Dos frascos de cultivo de células CMTO, fueron mantenidos durante 24 horas a $37^{\circ} \mathrm{C}$ y $5 \%$ de $\mathrm{CO} 2$, sin exposición al glicoalcaloide (ensayos A y B) y fueron tratados como grupo control de solanina. Los otros dos frascos de cultivo se expusieron durante 24 horas a una concentración de $4 \mu \mathrm{M}$ de $\alpha$-solanina con las mismas condiciones de temperatura y CO2 (ensayos C y D). Todos los tratamientos fueron realizados por duplicado.

\section{Tinción con Tinta China}

Dos de los frascos de cultivo (ensayos B y D) fueron teñidos directamente con $30 \mu \mathrm{l}$ de Tinta China cada uno. La Tinta China utilizada fue tinta acuosa libre de aceite y de secado rápido, Pelikan \#17 Schwarz Black (ref. 70306 4340503), filtrada antes de su utilización en papel filtro Whatman \#2125 mmØ (cat No.1002-125).

Se realizaron movimientos circulares suaves a los frascos hasta obtener un color homogéneo. Después de 3 minutos, tiempo considerado necesario para permitir el contraste, se extrajo, con una pipeta Pasteur, el medio de cultivo coloreado en su totalidad. Al mismo tiempo, se hizo la depuración de las células no adheridas. Las células adheridas a los frascos se lavaron 2 veces con $1 \mathrm{ml}$ de Buffer fosfato salino (PBS) cada una, con el objeto de eliminar el exceso de medio y de tinta. 
El exceso de PBS se eliminó haciendo movimientos fuertes de los frascos de cultivo con la boca de estos hacia abajo, se dejaron sin tapa y en reposo por 2 minutos, permitiendo que se secara cualquier exceso de líquido alrededor de las células.

\section{Microscopia invertida}

Se realizó la observación directa en lo frascos de cultivo utilizando microscopia óptica invertida (40X) y se procedió al conteo manual de 200 células por frasco de cultivo.

Se enfatizó en la descripción de las células de acuerdo con la nitidez observada y a la facilidad de conteo de las células, luego de la exposición al citotóxico y a la tinción con Tinta China.

Se comparó la nitidez observada (adecuada apreciación del borde de las estructuras) entre los grupos de células con y sin Tinta China. Se obtuvieron las frecuencias relativas de células observadas con nitidez y sin nitidez en cada uno de los grupos y se compararon las proporciones, con test exacto de Fisher, considerando una diferencia estadísticamente significativa con una $\mathrm{p}>0.05$.

\section{Fijación}

Una vez observadas y cuantificadas, las células fueron fijadas con una solución de para formaldehido al 0,4\% (14) logrando una exitosa preservación de las células y de los cultivos.

\section{Resultados}

La mejoría en la nitidez, posterior a la tinción con tinta China, hizo evidentes las diferencias cualitativas de las células antes y después de la exposición al glicoalcaloide. La tinta hizo visibles características celulares no observadas en el grupo sin teñir, como bordes regulares, distribución característica de pigmento citoplasmático, características fibroblastoides clásicas y diferencias claras entre la forma y tamaño de sus prolongaciones, así como también hizo evidentes conformaciones morfológicas de diferentes números de células

La Tinta China permitió detallar cada una de las células hasta el punto de poder observar diferencias claras en la condensación citoplasmática, evidenciar cambios morfológicos secundarios a la retracción del citoplasma, así como una disminución del tamaño celular y la presencia de espículas o prolongaciones de mayor longitud.

Las diferencias en nitidez fueron evidentes entre los frascos teñidos y los no teñidos con Tinta China (Fig. 1)

Se observaron bordes marcados, definidos y nítidos, que permitieron una caracterización celular adecuada y una fácil cuantificación (Fig. 1 B y D). Mientras que la evaluación directa de las células en monocapa, por medio de la microscopía invertida, no permitió una visualización nítida de las características fenotípicas de las células en los ensayos A y C, lo que ocasionó problemas en la definición de las membranas y dificultó la cuantificación de las células. (Fig. 1 A y C).

(A) Resultado de observación directa de CTMO no expuestas a $\alpha$-solanina sin Tinta China. d: se aprecian células poco definidas y heterogéneas en su apariencia, células alargadas parecidas a fibroblastos. t: células redondeadas y células aplanadas con estructuras translucidas interferentes. (B) Detalle de células no expuestas a $\alpha$-solanina, visualizadas con Tinta China, en donde se observa mayor definición de las membranas y aumento de la nitidez en pigmento intracelular marcado (Flechas m e i) con mayor intensidad en áreas adyacentes a las membranas celulares. (C) CTMO expuestas a $\alpha$-solanina $(4 \mu \mathrm{M})$, sin Tinta China e: células con alargamientos en forma de espículas poco definidas. p: baja definición intracelular de zonas pigmentas. (D) Células expuestas a $\alpha$-sola- 
nina $(4 \mu \mathrm{M})$, con Tinta China. n: Se aprecia la mejora de la nitidez en la mejor visualización de forma, estructura celular y de los alargamientos tipo espícula. h: presencia de halo refringente circundante que podría deberse a condensación de la cromatina y alteraciones de membrana que eventualmente estarían relacionados con el grado de daño ocasionado por la sustancia citotóxica.

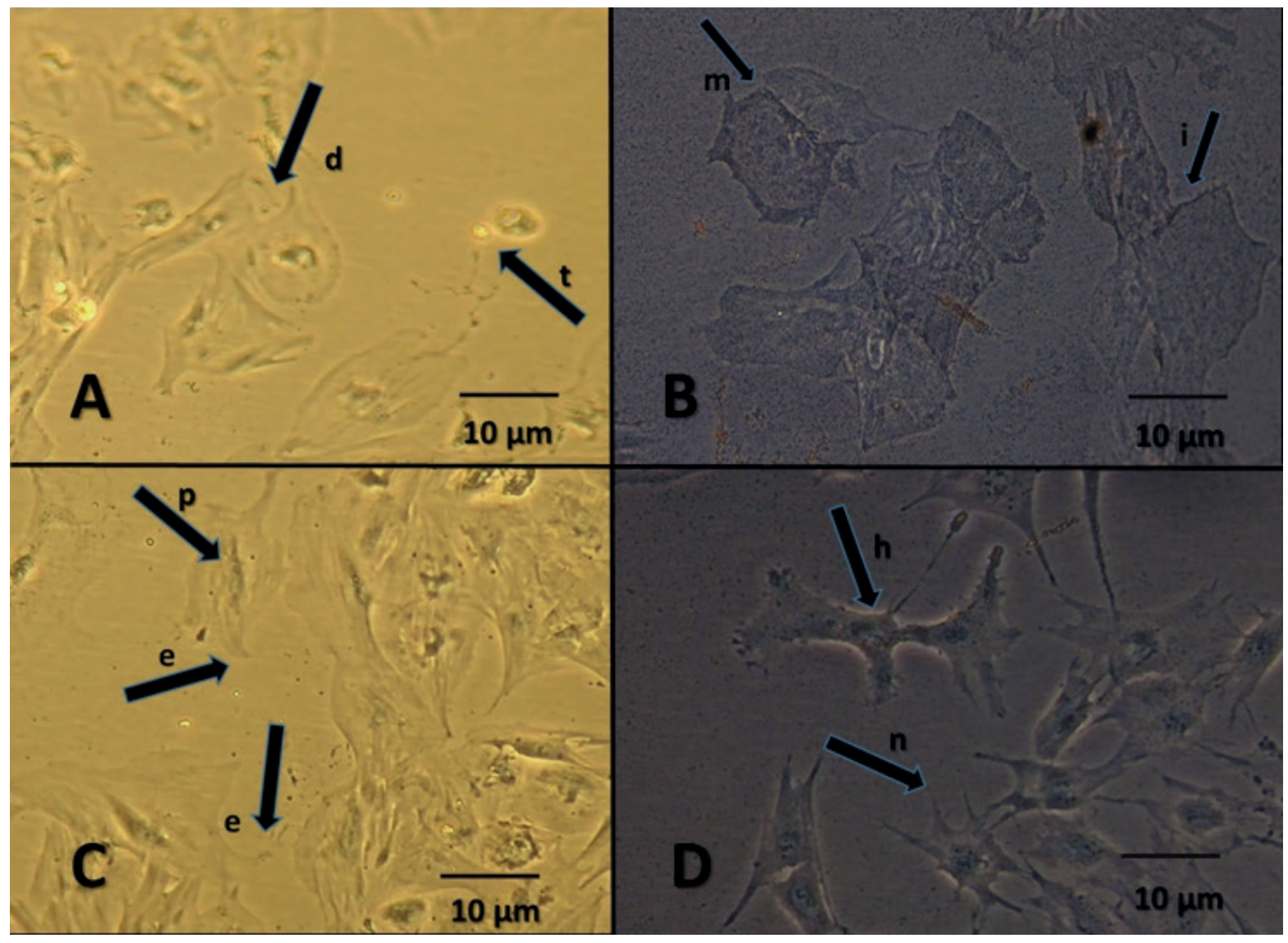

Figura 1. Células troncales de medula ósea de rata en cultivo primario de 24 horas adheridas al medio de cultivo y observadas en microscopio invertido a $60 \mathrm{X}$.

Después de la exposición al glicoalcaloide, se encontraron diferencias marcadas entre el grupo teñido con Tinta China y el grupo sin teñir. En el ensayo $\mathrm{C}$, se observan algunas diferencias con las células no expuestas al citotóxico, sin embargo, estos cambios son poco claros y sin definición. Mientras que en el ensayo D que fue teñido con Tinta China, se alcanzó total nitidez en la observación y mayor certeza en el conteo, confirmando de una manera cualitativa, el efecto tóxico de la sustancia sobre las células. Estos ensayos también permitieron establecer que el tiempo de inicio del efecto tóxico del glicoalcaloide, representado por cambios morfológicos y agrupamiento celular (Fig. 2) es de 12 horas luego de la exposición.

Al ser esta una tinción negativa, las zonas más oscuras son las zonas menos condensadas. (a) Célula viva, adherida al frasco de cultivo con bordes regulares y pigmento localizado de forma característica en citoplasma y núcleo. (b, c y d): alargamientos en forma de espículas, con diferentes grados de alargamiento. (e y f): agrupamiento celular en forma de rosetas, compuestas por cinco células agrupadas (e) y tres células (f), apiñadas con bordes definidos que permiten su fácil conteo. 
Otros detalles intracelulares visibles con esta técnica, (g): membrana plasmática, línea teñida que delimita la célula y el medio externo (h): citoplasma celular, zona teñida, oscura no uniforme, que permite evidenciar la presencia de organelos. (i): núcleo, forma única circular no teñida dentro del citoplasma. (k): nucléolo, estructura puntiforme de color oscuro, contenida en el núcleo.

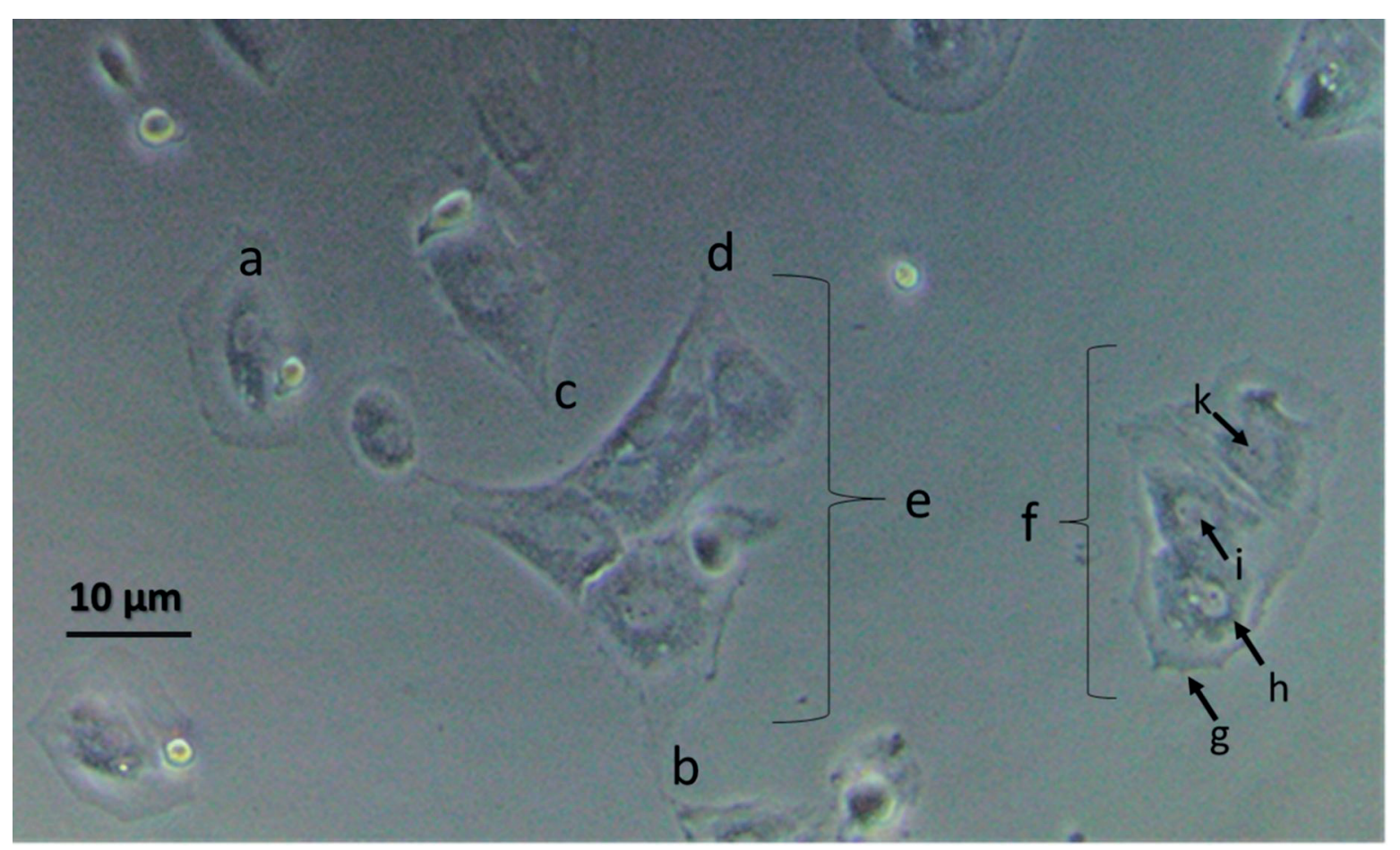

Figura 2. CTMO adheridas a cultivo posteriores a la exposición durante 12 horas a $\alpha$-solanina $(4 \mu \mathrm{M})$ coloreadas con Tinta China visualizadas con aumento de 60X.

De las 400 células observadas en el grupo sin Tinta China (ensayos A y C) se observaron con nitidez 147 células (37\%). En los frascos teńidos con Tinta China (ensayos B y D) todas las células $(100 \%)$ se apreciaron nítidas y fácilmente identificables $(\mathrm{p}<0.0001)$

La tinción con Tinta China permitió evidenciar los cambios fenotípicos posteriores a la exposición al glicoalcaloide y así establecer con certeza, una relación entre el efecto del glicoalcaloide y los cambios en la morfología de este tipo de células directamente en cultivo.

\section{Discusión}

De acuerdo con Kunjappu (15), la Tinta China es un sistema complejo de tipo coloidal basado en partículas de pigmento finas de carbón, dispersas en un disolvente acuoso u orgánico. La tinta tiene ingredientes que incluyen modificadores de $\mathrm{pH}$, humectantes para retardar el secado prematuro, resinas poliméricas para impartir propiedades de unión, agentes antiespumantes para regular la eficiencia, agentes tensoactivos para controlar las propiedades de superficie y espesantes y biocidas que inhiben el crecimiento de hongos y bacterias. 
La Tinta China ha tenido diversos usos que incluyen desde la caligrafía, hasta experimentos de marcaje y diafanización, así como la visualización de perfusión por vía endovenosa $(16,17)$. Es la base preferente de la tinción negativa en el laboratorio clínico $(18,19)$, en donde es utilizada en el diagnóstico microbiológico directo en líquido cefalorraquídeo del hongo Cryptococcus neoformans, el cual, por estar cubierto con una capsula de polisacáridos, se hace fácilmente visible con ésta tinta. También se utiliza en muestras de materia fecal, en donde el parásito Blastocystis spp., es fácilmente visualizado (20) y a través de la técnica reportada por Zerpa y cols., la combinación de Tinta China con mercurio cromo al $2 \%$, es posible identificar variaciones morfológicas del parásito (21).

Aunque no se encontró en la literatura revisada, ninguna referencia acerca de la utilización de Tinta China como tinción directa en células adheridas en cultivo, sus propiedades fueron aprovechadas en este trabajo por ser una tinción no invasiva, económica, rápida y de muy fácil consecución. $\mathrm{Al}$ ser líquida, la tinta alcanza a entrar en el espacio que separa la monocapa de células adheridas de la base lisa del frasco de cultivo, permitiendo que las partes más condensadas de la célula impidan ver el color de la tinta debajo de ellas, por lo que estas partes condensadas se ven más claras e incluso refringentes y las partes menos condensadas de la célula, se hacen evidentes porque son más oscuras, es decir, permiten ver el color oscuro de la Tinta China debajo de ellas.

De otra parte, ésta tinción hace que el tamaño de las células sea muy similar al real, contrario al resultado usual después de la fijación celular, dado que luego de este proceso, el cual es necesario para la visualización de células con otras tinciones, se produce el encogimiento de las células disminuyendo la precisión de las observaciones.

La utilización de este tipo de técnicas básicas de laboratorio permite realizar observaciones de células adheridas en cultivo, antes y después de la exposición a medicamentos o citotóxicos y contribuye a la definición del rango de concentraciones a utilizar en los experimentos, debido a que la magnitud de los efectos es fácilmente observable.

Usualmente los pasos preparatorios a la lectura microscópica, involucran la fijación de la muestra que, aunque pretende conservar la forma de las células o tejidos involucrados tanto como sea posible, no permite la viabilidad de las células (tal como la fijación por calor) o generan enlaces químicos entre proteínas y otras sustancias dentro de la muestra, aumentando su rigidez. La fijación antes de la tinción con Tinta China no es necesaria, dado que después de comparar las células sin teñir y las células teñidas, se evidenció que la forma y tamańo de las células en monocapa se conserva y no hace necesarios pasos ulteriores de fijación y nueva valoración morfológica. El uso potencial de esta técnica radica en la facilidad de implementación directa en cultivo, en el poco tiempo de tinción, en la no utilización de otros reactivos, en la utilización de cultivos a bajo costo y en la posibilidad de aplicación en la observación directa de otras células fibroblastoides en cultivo.

Vale la pena comentar que, entre las ventajas en la utilización de las CTMO, están su fácil aislamiento, rápida expansión en el medio de cultivo y la estabilidad genética, por lo que se considera que estas células fueron usadas con éxito en este experimento. En condiciones normales estas células se encuentran dispersas en el cultivo, son pequeñas, largas y estrechas y la matriz extracelular adyacente está formada por algunas fibrillas reticulares (22).

Al conocer las características de las células normales se pudo hacer una comparación directa entre las células sin exposición al glicoalcaloide y posterior a esta, encontrándose diferencias concretas en tamańo, bordes, longitud de las prolongaciones o espículas y condensación citoplasmática. 
Se sugiere que estos cambios se deben a la acción de la sustancia citotóxica que se acumula principalmente en citoplasma y vacuolas, inhibiendo la colinesterasa y el funcionamiento de la bomba sodio-potasio ATPasa (23). Los efectos de la $\alpha$-solanina no son muy conocidos, pero posiblemente se relacionan con daños en la ruta de la pentosa fosfato y en las vías de genes BMP (Bone morphogenetic protein), WNT/ $\beta$ - catenina, $y$ Trio - RhoA-Shroom3 (24, 25). Después de la exposición al glicoalcaloide, las células reaccionan con alargamientos de algunas fibrillas reticulares que adquieren forma de espículas, seguramente buscando una mayor adhesión, como consecuencia de la trasmisión de señales paracrinas que son el mecanismo de inducción responsable de su potencial para la reparación de tejidos (repertorio morfogenético) (26-28).

\section{Conclusión}

La determinación cualitativa de los cambios a nivel de morfología celular posteriores a la exposición con $\alpha$-solanina utilizando Tinta China es un método no invasivo, novedoso, rápido y sencillo que sirve para monitorear la acción del glicoalcaloide en cultivos de células vivas adheridas en monocapa.

\section{Referencias}

1. Swanson, M., et al., A screening method for ranking and scoring chemicals by potential human health and environmental impacts. 1997. 16(2): p. 372-383. doi: $10.1002 /$ etc. 5620160237 .

2. Leist, M. and M. Jaattela, Triggering of apoptosis by cathepsins. Cell Death Differ, 2001. 8(4): p. 324-6. Citado en PubMed PMID: 11550083

3. Strober, W., Trypan Blue Exclusion Test of Cell Viability. Curr Protoc Immunol, 2015. 111: p. A3 B 1-3. doi: 10.1002/0471142735. ima03bs111. Citado en Pubmed PMID: 26529666.

4. Repetto, G., A. del Peso, and J.L. Zurita, Neutral red uptake assay for the estimation of cell viability/cytotoxicity. Nat Protoc, 2008. 3(7): p. 1125-31. doi: 10.1038/nprot.2008.75. Citado en Pubmed PMID: 18600217.
5. Olsson, T., et al., Leakage of adenylate kinase from stored blood cells. J Appl Biochem, 1983. 5(6): p. 437-45. Citado en Pubmed PMID: 6088465.

6. Corey, M.J., et al., A very sensitive coupled luminescent assay for cytotoxicity and complement-mediated lysis. J Immunol Methods, 1997. 207(1): p. 43-51. Citado en Pubmed PMID: 9328585.

7. Cho, M.H., et al., A bioluminescent cytotoxicity assay for assessment of membrane integrity using a proteolytic biomarker. Toxicol In Vitro, 2008. 22(4): p. 1099-106. doi: 10.1016/j. tiv.2008.02.013. Citado en Pubmed PMID: 18400464.

8. Burch, C.R. and J.P.P. Stock, Phase-contrast microscopy. Journal of Scientific Instruments, 1942. 19(5): p. 71.

9. Tan, Y.F., C.F. Leong, and S.K. Cheong, Observation of dendritic cell morphology under light, phase-contrast or confocal laser scanning microscopy. Malays J Pathol, 2010. 32(2): p. 97-102. Citado en Pubmed: 21329180.

10. Digan, M.E., et al., Evaluation of division-arrested cells for cell-based high-throughput screening and profiling. J Biomol Screen, 2005. 10(6): p. 615-23. Citado en Pubmed: 16103416.

11. Gillespie, A.W., et al., Glomalin-related soil protein contains non-mycorrhizal-related heat-stable proteins, lipids and humic materials. Soil Biology and Biochemistry, 2011. 43(4): p. 766-777. doi:10.1016/j.soilbio.2010.12.010

12. Tangarife-Tobón, L., L. Jaramillo-Gómez, and C. DuránCorrea, Cultivo de células troncales de médula ósea de rata (rctmo) en matrices de colágeno tipo i, para su uso en Protocolos de regeneración de tejidos in Centro de Investigaciones Odontológicas. 2014, Pontificia Universidad Javeriana: Bogotá.

13. Lu, M.K., et al., alpha-Solanine inhibits human melanoma cell migration and invasion by reducing matrix metalloproteinase-2/9 activities. Biol Pharm Bull, 2010. 33(10): p. 1685-91.Citado en Pubmed: 20930376

14. Martín-Lacave, I. and T. García-Caballero, Atlas de Inmunohistoquímica: Caracterización de células, tejidos y organos normales. 2012, Ediciones Díaz de Santos, S.A. p. 22.

15. Kunjapu, J.T., Essays in ink chemistry. 2001, New York: Nova Science.

16. Gutiérrez, E. and R. Garcia, Estudio comparativo in vitro para medir la microfiltración en obturación retrógrada con PRO ROOT ${ }^{\oplus}, \mathrm{CPM}^{\circledast}$ y Súper-EBA ${ }^{\oplus}$ Revista Odontológica Mexicana, 2007. 11(3): p. 140-144.

17. Greco-Machado, Y., et al., Técnicas de diafanización: estudio comparativo. Endodoncia, 2008. 26(2): p. 85-92.

18. Lengua-Almora, F., E. Herrera-Zuleta, and J. Kunlin, Nuevos documentos experimentales de inversión circulatoria en miembro isquémico y de inyección retrógrada en piezas anatómicas. Diagnóstico (Perú), 1984. 13(3): p. 77-86.

19. Padilla, S., et al., Trasplante de células mononucleares progenitoras derivadas de médula ósea por vía endovenosa retrógrada distal para inducir angiogénesis en miembros inferiores con isquemia. Cir Gen, 2009. 31(4): p. 213-218. 
20. Zapata-Valencia, J. and C. Rojas-Cruz, Una actualización sobre Blastocystis sp. Revista Gastrohnup 2012. 14(3): p. 94-100.

21. Zerpa, R. and L. Huicho, Tinta China modificada para la detección de formas encapsuladas de Blastocystis hominis. Rev. mex. patol. clin, 1999. 46(3): p. 184-186.

22. Brighton, C.T. and R.M. Hunt, Early histological and ultrastructural changes in medullary fracture callus. J Bone Joint Surg Am, 1991. 73(6): p. 832-47. Citado en Pubmed: 2071617.

23. Yamashoji, S. and T. Matsuda, Synergistic cytotoxicity induced by alpha-solanine and alpha-chaconine. Food Chem, 2013. 141(2): p. 669-74. Citado en Pubmed: 23790833.

24. McGreevy, E.M., et al., Shroom3 functions downstream of planar cell polarity to regulate myosin II distribution and cellular organization during neural tube closure. Biol Open, 2015. 4(2): p. 186-96. doi: 10.1242/bio.20149589. Citado en Pubmed: 25596276.
25. Cibois, M., et al., BMP signalling controls the construction of vertebrate mucociliary epithelia. Development, 2015. 142(13): p. 2352-63. doi: 10.1242/dev.118679. Citado en Pubmed: 26092849 .

26. Yu, T., et al., Stem Cells in Tooth Development, Growth, Repair, and Regeneration. Curr Top Dev Biol, 2015. 115: p. 187-212. doi: 10.1016/bs.ctdb.2015.07.010. Citado en Pubmed: 26589926.

27. Nausa, J. G. (2014). “Evaluación Clínica y radiográfica de injertos biocerámicos tipo Hidroxiapatita como alternativa en la reconstrucción de alveolos dentarios postexodoncia."

28. Páez, L. C. C., et al. (2015). "Comparación del cultivo celular de HeLa y HEp-2: Perspectivas de estudios con Chlamydia trachomatis." Nova 13(23). 